\title{
BMJ Open What is the impact on the readmission ratio of taking into account readmissions to other hospitals? A cross-sectional study
}

Karin Hekkert, ${ }^{1}$ Ine Borghans, ${ }^{2}$ Sezgin Cihangir, ${ }^{3}$ Gert P Westert, ${ }^{1}$ Rudolf B Kool ${ }^{1}$

To cite: Hekkert $\mathrm{K}$, Borghans I, Cihangir S, et al. What is the impact on the readmission ratio of taking into account readmissions to other hospitals? A crosssectional study. BMJ Open 2019;9:e025740. doi:10.1136/ bmjopen-2018-025740

- Prepublication history for this paper is available online. To view these files, please visit the journal online (http://dx.doi. org/10.1136/bmjopen-2018025740).

Received 31 July 2018 Revised 21 February 2019 Accepted 22 February 2019

Check for updates

(C) Author(s) (or their employer(s)) 2019. Re-use permitted under CC BY-NC. No commercial re-use. See rights and permissions. Published by BMJ.

${ }^{1}$ IQ healthcare, Radboud University Medical Center, Radboud Institute for Health Sciences, Nijmegen, The Netherlands

${ }^{2}$ Team Risk Detection, Dutch Health and Youth Care Inspectorate (IGJ), Utrecht, The Netherlands

${ }^{3}$ Team Expertise and Support, Dutch Hospital Data, Utrecht, The Netherlands

Correspondence to

Karin Hekkert;

karin.hekkert@radboudumc.nl

\section{ABSTRACT}

Objectives Readmissions are used widespread as an indicator of the quality of care within hospitals. Including readmissions to other hospitals might have consequences for hospitals. The aim of our study is to determine the impact of taking into account readmissions to other hospitals on the readmission ratio.

Design and setting We performed a cross-sectional study and used administrative data from 77 Dutch hospitals (2 333173 admissions) in 2015 and 2016 (97\% of all hospitals). We performed logistic regression analyses to calculate 30-day readmission ratios for each hospital (the number of observed admissions divided by the number of expected readmissions based on the case mix of the hospital, multiplied by 100). We then compared two models: one with readmissions only to the same hospital, and another with readmissions to any hospital in the Netherlands. The models were calculated on the hospital level for all in-patients and, in more detail, on the level of medical specialties.

Main outcome measures Percentage of readmissions to another hospital, readmission ratios same hospital and any hospital and $\mathrm{C}$-statistic of each model in order to determine the discriminative ability.

Results The overall percentage of readmissions was $10.3 \%$, of which $91.1 \%$ were to the same hospital and $8.9 \%$ to another hospital. Patients who went to another hospital were younger, more often men and had fewer comorbidities. The readmission ratios for any hospital versus the same hospital were strongly correlated $(r=0.91)$. There were differences between the medical specialties in percentage of readmissions to another hospital and C-statistic.

Conclusions The overall impact of taking into account readmissions to other hospitals seems to be limited in the Netherlands. However, it does have consequences for some hospitals. It would be interesting to explore what causes this difference for some hospitals and if it is related to the quality of care.

\section{INTRODUCTION}

Widespread use is made of readmissions as an indicator of the quality of care within hospitals. ${ }^{1-4}$ Hospitals themselves use the indicator to measure and improve their quality of care ${ }^{56}$ while governments use readmissions
Strengths and limitations of this study

- First study in the Netherlands that analyses the impact of taking into account readmissions to other hospitals.

- The database contains all hospital admissions of nearly all Dutch hospitals ( $97 \%$ of the general and university hospitals).

- Not all hospitals register the unique patient numbers completely, which could affect the readmission rate when including readmissions to other hospitals.

- The database does not contain a variable that distinguishes between intended and unintended readmissions.

for rankings and financial penalties. ${ }^{7} 8$ Because of their presumed relationship to the quality of care, and the extra costs associated with them, hospitals should monitor the number of readmissions carefully. ${ }^{19-12}$ Monitoring readmissions can be done using existing administrative data without an additional burden for healthcare professionals. ${ }^{13}$ However, the interpretation of readmissions is complicated by the fact that there are many reasons for them. ${ }^{14}$ Moreover, there are several ways of calculating readmission rates, depending on the objective of the readmission measure and the data availability. ${ }^{215}$

One of the issues in the existing readmission indicators is the inclusion of readmissions to other hospitals. Hospitals can assess, monitor and analyse their own readmissions, and track down their causes, in order to improve quality and safety. However, it is plausible that patients are also readmitted to other hospitals. This may occur, for example, after a complication in the first hospital or when patients are not satisfied with the care delivered in the original hospital. It is important to be aware of the impact of readmissions to other hospitals in order to benchmark readmissions fairly. This impact can differ per 
hospital. ${ }^{16}$ In addition, that part of readmissions which are to other hospitals might differ per medical specialty. For example, a difference might exist between surgical and diagnostic specialties. It is important to take this into account when interpreting readmission outcomes if one is to seek potential improvements. We expect that the impact of taking into account readmissions to other hospitals differs between hospitals and medical specialties, and that this can reveal additional opportunities for improvement.

Several studies have shown a substantial impact when readmissions to other hospitals are included. Depending on its definition, readmissions occurring in other hospitals can vary from between $17 \%$ and $32 \%$ of the total number of readmissions. ${ }^{16-23}$ Halfon $e t a l^{17}$ and Nasir $e t a l^{16}$ specifically mentioned that the part of the readmissions that occurred in another hospital varied substantially between hospitals. This is an additional reason to take this mechanism into account. However, most of these studies are performed in the USA so it is not known if these results are also applicable for European countries with different healthcare systems, such as the Netherlands. The Dutch healthcare system is based on mandatory private health insurance with an important role for the general practitioner (GP) acting as the gatekeeper of secondary care. They play a crucial role in referrals to hospitals and can be directive in their choice of hospitals. The question is therefore whether the abovementioned impact, resulting from the inclusion of readmissions to other hospitals, is the same for other countries. It is important to answer this question because, in the Netherlands, readmissions are an indicator of the quality of care. The Dutch Health and Youth Care Inspectorate requires that hospitals publicly submit their overall number of readmissions each year. ${ }^{24}$ There are no financial penalties for hospitals with more readmissions than the national average (readmission ratio $>100$ ). At the moment, this concerns only readmissions within the same hospital.

The aim of this study is to assess the difference between case mix adjusted readmission ratios for each hospital including readmissions to other hospitals and those based solely on readmissions which occur in the same hospital. The research question is: what is the impact on the readmission ratio of taking into account readmissions to other hospitals?

\section{METHODS}

\section{Database and study population}

We used data from the Dutch National Basic Registration of Hospital Care (LBZ). ${ }^{25}$ This database provides data from all 79 general and university hospitals in the Netherlands-at the time of the study period-and contains all hospital admissions. Dutch Hospital Data, the national organisation that administers the data from all the hospitals, gave permission to use the data anonymously. We selected index admissions with a discharge date from 1 January 2015 to 31 October 2016, and all subsequent readmissions until a discharge date of 31 December 2016. The data used in this study is fully anonymised and publicly available for researchers via Remote Access to Statistics Netherlands (CBS). We had permission of all hospitals to use the data anonymously.

The definition of a readmission was a clinical admission to the same hospital, within 30 days of discharge, following the clinical index admission-that is, the original hospital stay. We chose this time frame in accordance with the international literature. ${ }^{1426}$ We calculated all-cause readmissions meaning that they do not need to be related to the cause of the initial hospitalisation. ${ }^{26} 27$ We used the index admission as the unit of analysis. This means that each readmission of the same patient is again an index admission for a subsequent readmission. ${ }^{28}$

Index admissions and readmissions were linked with a unique patient number obtained by a Trusted Third Party (Zorg TTP) which allows an individual's information in healthcare to be exchanged without compromising their privacy. Readmissions were assigned to the hospital of the index admission. Transfers, which are defined as readmissions to another hospital within 1 day, ${ }^{29}$ were not counted as readmissions but included as an index admission of the second hospital.

We excluded hospitals that did not register unique patient numbers. We also excluded admissions that were not registered completely in the database (for example, missing diagnosis). Patients not living in the Netherlands were excluded as either their index admission or their readmission, could have taken place in their country of residence and therefore readmissions could be underestimated. Patients who died during their index admission were excluded from the population at risk. Furthermore, we excluded admissions where data were missing on one of the variables that we used in the analyses. Based on previous literature, we also excluded admissions in which the principal diagnosis involved either cancer care, obstetrics or psychiatric care. ${ }^{30}$

Hospitals with inadequate quality of data were also excluded. In order to assess the quality of data, we investigated the following criteria ${ }^{31}$ : there should be at least 12 consecutive months of data registration; not $>2 \%$ of vague diagnoses; at least $30 \%$ acute admissions; and at least 0.5 comorbidities, on average, per admission. We assessed these variables because they are subject to variations in coding between different hospitals ${ }^{31}$ and are important in the calculation of readmissions. Acute admissions and admissions with multiple comorbidities have a higher risk of readmission. ${ }^{13}$ Hospitals that did not meet one or more criteria were excluded from the analyses.

\section{Design}

We performed logistic regression analyses to calculate readmission ratios for each hospital based on the administrative data. We did not perform hierarchical modelling, as a recent study showed that adding a hospital level had only a very small impact on the results. ${ }^{32}$ The following predicting covariates for the adjustment for 
case mix were used $^{33} 34$ : severity of main diagnosis (a categorisation depending on the seriousness in terms of mortality), gender, age category, urgency of the admission, Charlson comorbidities (17 groups of comorbidity), socioeconomic status (based on the postal code of the patients' residence), month of admission and place of residence before admission. All variables concern the index admission.

\section{Patient and public involvement}

Patients were not involved in the design of this study.

\section{Analysis}

We calculated the baseline characteristics of the subset of readmissions in the dataset, comparing these characteristics for readmissions to the same hospital with readmissions to other hospitals. We calculated readmission ratios for each hospital by dividing the observed number of readmissions by the expected number of readmissions, multiplied by 100 . The expected number of readmissions is based on the case mix of the hospital. Two models were designed, one including only readmissions to the same hospital, while the other included readmissions to any hospital. We compared the readmission ratios of both models and calculated the correlation between both models with $\mathrm{r}$.

We calculated $95 \%$ CIs for the readmission ratio of each hospital to analyse if it differed from the national average (readmission ratio of 100). Subsequently, we calculated the number of hospitals whose position of significance compared with the national average changed when taking into account readmissions to any hospital compared with the same hospital. A change in position of significance can be, for example, from significantly lower than the national average to no significant difference from the national average.

The models were calculated on the hospital level for all in-patients and in more detail on the level of medical specialties. The C-statistic of each model was calculated in order to determine the discriminative ability. We analysed the difference in C-statistic between the models including only readmissions to the same hospital, and the models with readmissions to any hospital, for each medical specialty.

Variables with fewer than 50 admissions in a category were merged with the smallest nearby category. This was done to prevent the SEs of the regression coefficients becoming too large. Comorbidities 9 and 17 (liver disease and severe liver disease), and 10 and 11 (diabetes and diabetes complications), were merged into one when there were fewer than 50 admissions where the comorbidity was present. Comorbidities with fewer than 50 admissions were not included in the regression analysis. We calculated the part of the readmissions to other hospitals for each medical specialty. Furthermore, we analysed which part of the readmissions to other hospitals concerned readmissions to general hospitals, leading hospitals undertaking clinical research and university hospitals.

The data were analysed using R V.3.2.3. The package pROG was used to calculate the C-statistic.

\section{RESULTS}

The database contained 2333173 admissions in 77 hospitals eligible for further analyses. See figure 1 for all factors which resulted in hospitals or admissions being excluded from the study.

The mean age of the patients was 55 years and there were slightly more women. The admissions were more often acute than non-acute. This was especially the case with readmissions (table 1 ).

There were differences in the characteristics of readmissions to the same hospital versus readmissions to other hospitals (table 1). Patients readmitted to another hospital were younger, more often men and had fewer comorbidities. It concerned more often a non-acute index admission, but, the readmission, especially, was more often non-acute. The three most frequently occurring diagnosis groups of the readmission to the same hospital were complications of surgical procedures or medical care; chronic obstructive pulmonary disease and bronchiectasis; and complications with a medical device, implant or graft. The three most frequently occurring diagnosis groups of the readmission to another hospital were coronary atherosclerosis and other heart disease, cardiac dysrhythmias and complications of surgical procedures or medical care.

The percentage readmissions of all admissions was $10.3 \%$, of which $91.1 \%$ was to the same hospital and $8.9 \%$ to another hospital (table 2). When looking at acute admissions only, the percentage readmissions was lower $(9.4 \%)$, of which a smaller percentage occurred in other hospitals $(5.2 \%)$.

The readmission ratios for any hospital versus the same hospital were strongly correlated (figure 2).

In total, $14 \%(=11 / 77$, marked grey in table 3$)$ of the hospitals changed their position of significance compared with the national average when taking into account readmissions to any hospital compared with the same hospital (table 3).

When looking at the different types of hospital, such as university hospital, leading clinical hospital or general hospital, it is only the leading clinical hospitals that changed their position of significance compared with the national average in a positive way, that is, to say from significantly higher, to no significant difference, or from no significant difference, to significantly lower. A change in position of significance in a negative way, that is, from significantly lower, to no significant difference, or from no significant difference, to significantly higher, was seen, especially, in university hospitals. This concerned 2 out of 7 university hospitals compared with 1 out of 42 for general hospitals and 2 out of 28 of teaching hospitals. 


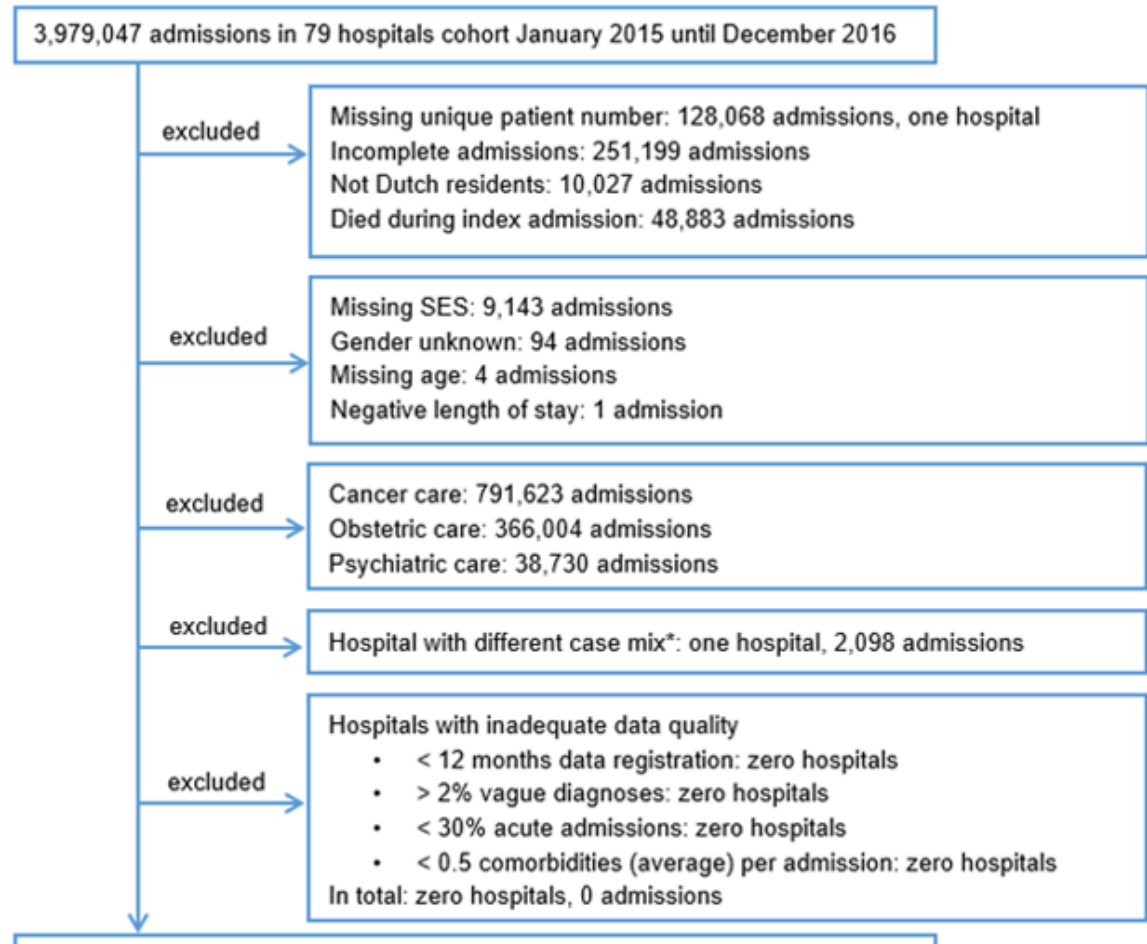

$2,333,173$ admissions in 77 hospitals remaining

- One hospital which had fewer than 100 readmissions per year, and treated only planned care and not

emergency care, was, therefore, excluded from the analysis.

Figure 1 Flowchart admissions in the dataset.

The percentage readmissions of all admissions differed between the medical specialities, from $2.9 \%$ of readmissions for oral and maxillofacial surgery to $18.5 \%$ readmissions for dermatology (table 4). The percentage of readmissions to other hospitals differed even more between the medical specialties, from $5.0 \%$ of readmissions to other hospitals for urology to $24.2 \%$ readmissions for cardiothoracic surgery. The type of hospital into which the patient was readmitted also differed per medical specialty. Patients discharged from cardiothoracic surgery were mainly readmitted to general and leading clinical hospitals, whereas patients discharged from paediatrics were mainly readmitted to university hospitals.

The C-statistics differed between the medical specialties (table 5). There were slight differences between the C-statistics of the models with readmissions to any hospital compared with the models with readmissions to the same hospital. For most medical specialties, the C-statistics of the models with readmissions to the same hospital were higher. The largest significant difference was found for

Table 1 Baseline characteristics of all admissions and readmissions in the dataset, N=77 hospitals

\begin{tabular}{|c|c|c|c|c|c|c|}
\hline \multirow[b]{2}{*}{ Variable } & \multicolumn{3}{|c|}{ All admissions } & \multicolumn{3}{|l|}{ Only readmissions } \\
\hline & Median & $\begin{array}{l}\text { 5th } \\
\text { percentile }\end{array}$ & $\begin{array}{l}\text { 95th } \\
\text { percentile }\end{array}$ & $\begin{array}{l}\text { Readmission same } \\
\text { hospital }(99.7 \% \mathrm{Cl})\end{array}$ & $\begin{array}{l}\text { Readmission other } \\
\text { hospitals (without } \\
\text { transfer) }(99.7 \% \mathrm{Cl})\end{array}$ & Significance \\
\hline Mean age & 55.41 & 50.64 & 59.17 & 59.86 (59.70 to 60.01$)$ & 56.09 (55.58 to 56.60$)$ & * \\
\hline \% Women & 50.59 & 47.49 & 53.60 & 46.72 (46.40 to 47.04$)$ & 43.70 (42.69 to 44.72$)$ & * \\
\hline $\begin{array}{l}\% \text { Admissions that was registered } \\
\text { as acute } †\end{array}$ & 60.18 & 47.57 & 70.49 & 71.62 (71.33 to 71.91$)$ & 68.48 (67.53 to 69.43$)$ & * \\
\hline $\begin{array}{l}\% \text { Readmissions that was } \\
\text { registered as acute }\end{array}$ & 74.38 & 66.09 & 81.10 & 75.85 (75.57 to 76.12$)$ & 59.97 (58.97 to 60.97$)$ & * \\
\hline Mean number of comorbidities & 0.47 & 0.28 & 0.67 & $0.76(0.76$ to 0.77$)$ & 0.64 (0.62 to 0.66$)$ & * \\
\hline
\end{tabular}

† In the Dutch National Basic Registration of Hospital Care (LBZ), an acute admission is an admission that cannot be postponed because immediate observation, examination and/ortreatment within 24 hours is necessary.

* Significant difference of concerning variable between readmission same hospital compared with readmission other hospitals $(99.7 \% \mathrm{Cl})$ 
Table 2 Number of readmissions and percentage of admissions, which of these occurs in other hospital, all admissions versus acute admissions only, $\mathrm{N}=77$ hospitals

\begin{tabular}{|c|c|c|}
\hline & $\mathbf{N}$ & $\%$ \\
\hline \multicolumn{3}{|l|}{ All admissions } \\
\hline Admissions total & 2333173 & \\
\hline Readmissions $<30$ days ( $\%$ of admissions) ${ }^{*}$ & 240122 & 10.29 \\
\hline $\begin{array}{l}\text { Readmissions }<30 \text { days of which in other } \\
\text { hospital }^{*} \% \text { of readmissions }<30 \text { days) }\end{array}$ & 21440 & 8.93 \\
\hline \multicolumn{3}{|l|}{ Acute admissions } \\
\hline Acute admissions total & 1370628 & \\
\hline $\begin{array}{l}\text { Acute readmissions }<30 \text { days ( } \% \text { of acute } \\
\text { admissions) }\end{array}$ & 128439 & 9.37 \\
\hline $\begin{array}{l}\text { Acute readmissions }<30 \text { days of which in } \\
\text { other hospital } \\
\text { ( } \% \text { of acute readmissions }<30 \text { days) }\end{array}$ & 8604 & 5.20 \\
\hline
\end{tabular}

${ }^{*}$ Transfers to another hospital were not counted as a readmission.

cardiothoracic surgery. For some medical specialties, the C-statistics of the models with readmissions to any hospital were higher. The largest significant difference for this group was found in paediatrics.

\section{DISCUSSION}

This study investigated the impact on the readmission ratio of taking into account readmissions to other hospitals.

\section{Comparison with other studies}

We found $10.3 \%$ of admissions resulted in readmissions to any hospital, which is comparable with a study of Davies et al which came up with a figure of $10.1 \%$ all-cause readmissions. ${ }^{22}$ However, the Davies study was limited to acute care hospitals. In our analysis, we found fewer, $9.4 \%$, readmissions when only looking at acute admissions and acute readmissions. Our analysis showed that $8.9 \%$ of the readmissions, both acute and non-acute, were in another hospital. This is low compared with the $17 \%-32 \%$ reported in other studies. ${ }^{16-23}$ These studies, however, concerned only acute care and were mainly carried out in the USA. When we limited our analysis to acute care, we found even fewer, $5.2 \%$, readmissions to other hospitals. This might indicate that the impact of taking into account readmissions to other hospitals is not comparable across different countries with different healthcare systems.

For most medical specialties, we found C-statistics of the models with readmissions to the same hospital that were significantly higher. The largest significant difference was for cardiothoracic surgery. This indicates better prediction of the same hospital ratio compared with the any hospital ratio. However, Gonzalez et $a l^{35}$ concluded that same hospital readmission rates provided unstable estimates of all-hospital readmission rates following coronary artery bypass grafting.

For some medical specialties, the C-statistics of the models with readmissions to any hospital we found were higher, with the largest significant difference for paediatrics. This indicates better prediction of the any hospital ratio compared with the same hospital ratio. A study by Kahn $e t a \hat{l}^{36}$ also concluded that different-hospital readmissions differentially affect hospitals' paediatric readmission rates. Our study found that $14 \%$ of the hospitals changed their position of significance compared with the national average when taking into account readmissions to any hospital compared with the same hospital. This is

\section{Readmission ratios - any hospital versus same hospital}

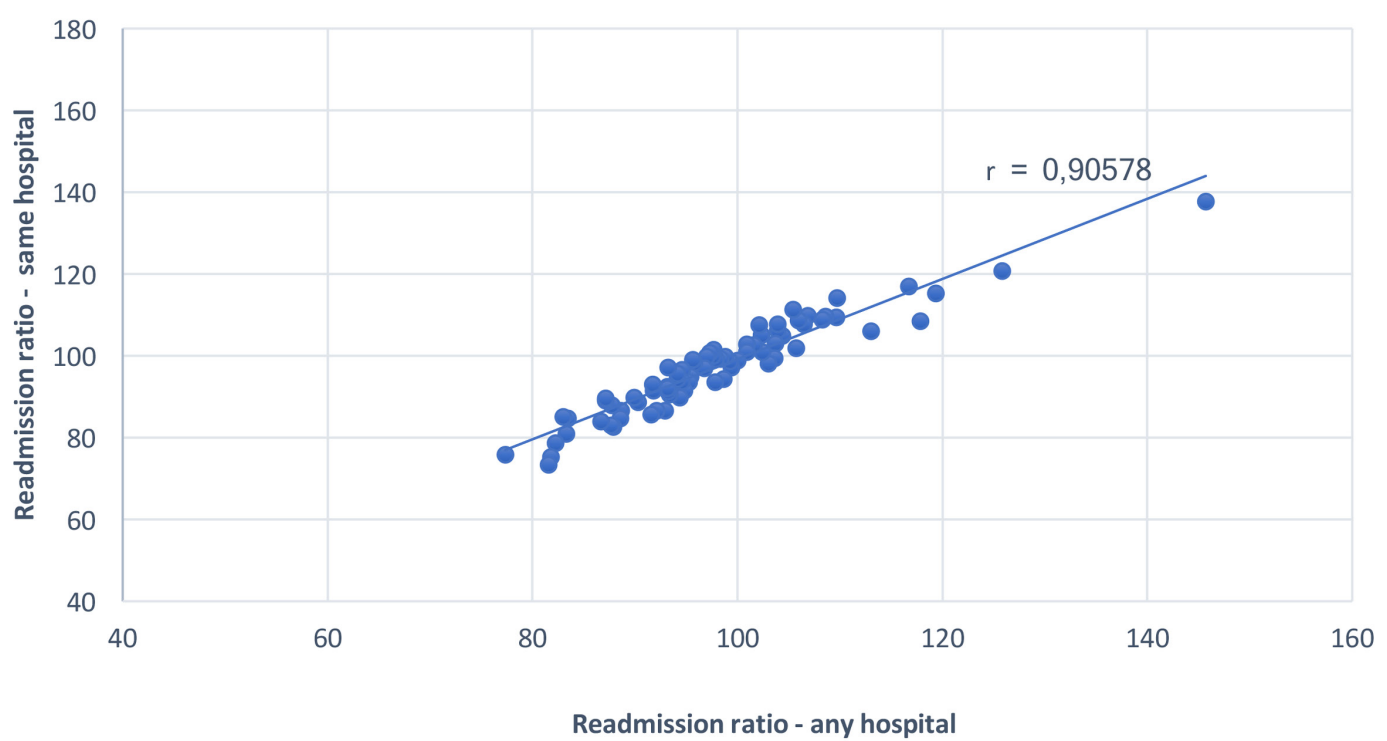

Figure 2 The plot readmission ratios for any hospital versus those readmissions for the same hospital, per hospital for all diagnosis groups. 
Table 3 Change of position of hospitals when using the readmission ratio* to same hospital versus that to any hospital

\begin{tabular}{|c|c|c|c|c|}
\hline \multirow[b]{2}{*}{ Readmission ratio-any hospital } & \multicolumn{4}{|c|}{ Readmission ratio - same hospital } \\
\hline & Significantly lower $(-1)$ & $\begin{array}{l}\text { No significant } \\
\text { difference }(0)\end{array}$ & $\begin{array}{l}\text { Significantly } \\
\text { higher (1) }\end{array}$ & Total \\
\hline No significant difference (0) & 2 & 14 & 2 & 18 \\
\hline Significantly higher (1)‡ & 0 & 3 & 17 & 20 \\
\hline
\end{tabular}

${ }^{*}$ Readmission ratio is the observed number of readmissions divided by the expected number of readmissions based on the case mix of the hospital, multiplied by 100 .

†Significantly lower readmission ratio means less readmissions compared with the national average.

$\ddagger$ Significantly higher readmission ratio means more readmissions compared with the national average.

quite comparable with the finding of Kahn et al (2015) that excluding different-hospital readmissions incorrectly anticipated penalties for $11 \%$ of hospitals.

\section{The Dutch healthcare system}

The small amount of readmissions to another hospital might be caused by the strong gatekeeping and referral role played by GPs in the Netherlands. These GPs usually have consistent addresses for referring patients. Each hospital has a wide range of medical specialities, and each hospital delivers emergency as well as elective care. Some hospitals are specialised and deliver, for example, more complex care in the field of heart disease. However, when this concerns patients from other hospitals, it often concerns a transfer. Therefore, they are not taken into the analysis and do not have an effect on the readmission rate to any hospital.

The high level of patient satisfaction in the Netherlands can also be a reason for the low percentage of readmissions to another hospital. In contrast to patients in the USA, Canada, the UK or Switzerland, in the Netherlands, more patients report that their regular doctor has spent enough time on their consultation, has given explanations which are easy to understand and has involved them in decisions about care or treatment. ${ }^{37}$ This high level of patient satisfaction could result in Dutch patients usually going to the same hospital.

\section{Strengths and limitations}

We believe the current study is the first in the Netherlands that analyses the impact of taking readmissions to other hospitals into account. Our finding that the impact is much smaller compared with the literature, could also apply to other countries with a comparable healthcare system to the Netherlands.

Another strength is the completeness of the national administrative database which covers all hospital admissions. In this study, we used 2333173 admissions from 77 hospitals, which is $97 \%$ of the general and university hospitals.

A limitation of the study is that not all hospitals register the unique patient numbers completely. In some hospitals, a few per cent of the readmissions do not have a unique patient number. This affects the results from surrounding hospitals as when one of their patients is readmitted to another hospital that did not register the unique patient number, this readmission could not be taken into account. Therefore, the readmission rate of these hospitals could be underestimated. We decided not to exclude the hospitals with incomplete unique patient number registrations, because then the impact on the readmission rate of the surrounding hospitals would be much larger. However, we had to exclude one hospital from our analysis, because they did not register unique patient numbers for all admissions. We expect that this has a negligible impact on our overall findings; however, it does affect the results from the surrounding hospitals.

It should also be mentioned that the Dutch National Basic Registration of Hospital Care, the LBZ, does not contain a variable that distinguishes between intended and unintended readmissions. In the LBZ, we do have the variable 'urgency' (acute vs non-acute admission) that indicates whether care within 24 hours is needed. ${ }^{25}$ A recent study reviewed medical records of readmissions to evaluate the accuracy of a classification of potentially preventable readmissions with LBZ data. ${ }^{37}$ It appeared that a larger proportion of acute readmissions was classified as potentially preventable compared with non-acute readmissions $(28.5 \%$ vs $5.0 \%)$. Nevertheless, we included both acute and non-acute admissions and readmissions in our study because complications might also result in readmissions that do not have a real 24-hour urgency and to avoid hospitals considering not to code the admission as acute in order to decrease their readmission ratio.

\section{Implications for practice}

Although the impact of taking into account readmissions to other hospitals is limited, this impact differs between hospitals. Therefore, these readmissions should be included in the readmission ratio, used in the Netherlands as a quality indicator, for a fair comparison between hospitals. However, its impact on the construct validity of the indicator is not known. It is important to include only readmissions that are related to the quality of care in the indicator and not readmissions that are a necessary part 


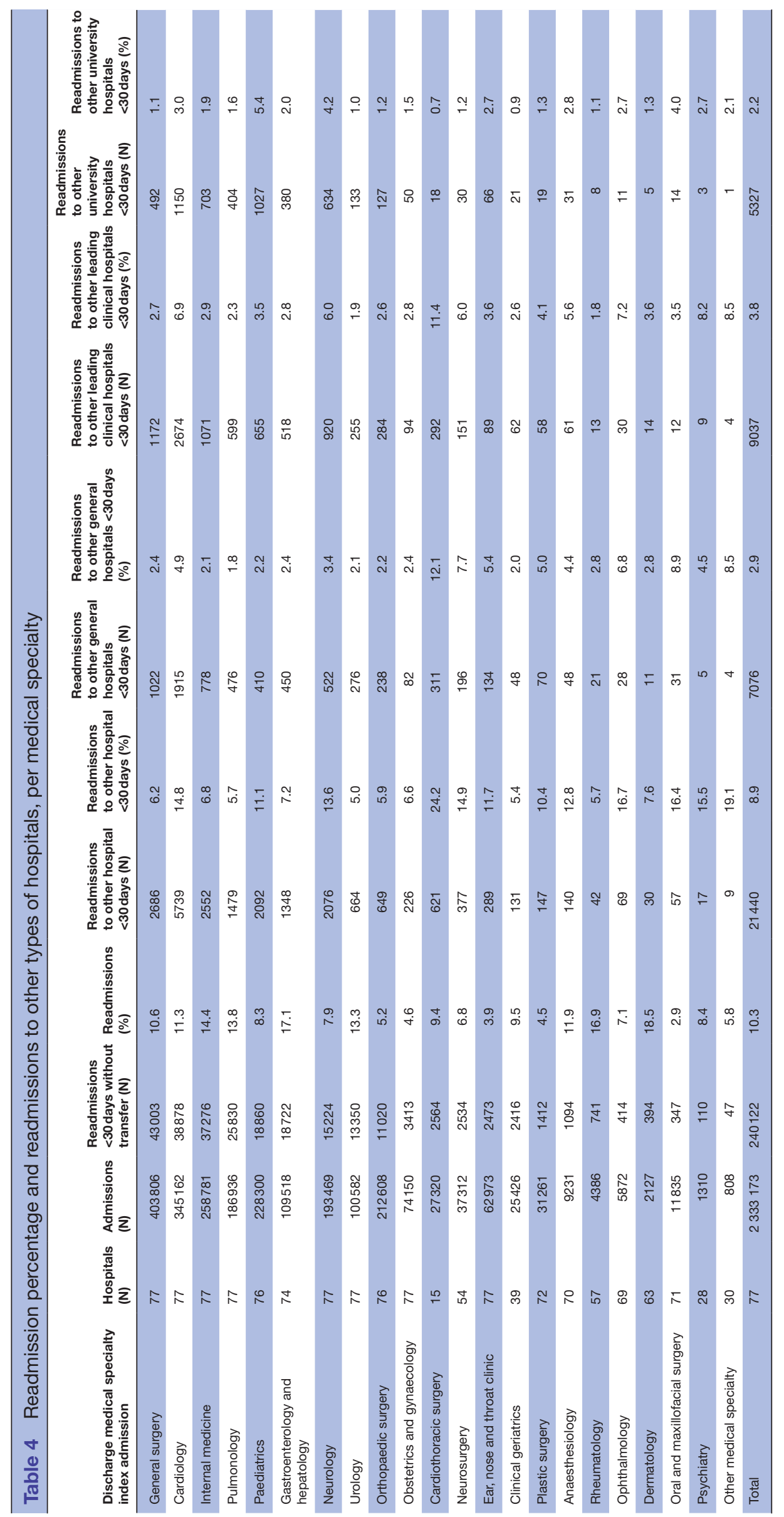

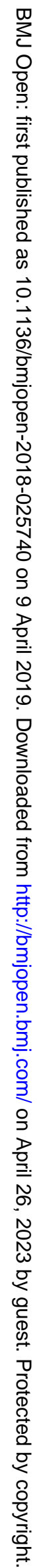


Table 5 C-statistics of the models per medical specialty, any hospital versus the same hospital

\begin{tabular}{|c|c|c|c|c|c|c|}
\hline $\begin{array}{l}\text { Discharge medical } \\
\text { specialty index admission }\end{array}$ & $\begin{array}{l}\text { C-statistic } \\
\text { model any } \\
\text { hospital }\end{array}$ & $\begin{array}{l}95 \% \mathrm{Cl} \\
\mathrm{C}-\mathrm{ctatistic} \text { model } \\
\text { any hospital }\end{array}$ & $\begin{array}{l}\text { C-statistic } \\
\text { model same } \\
\text { hospital }\end{array}$ & $\begin{array}{l}95 \% \mathrm{Cl} \\
\mathrm{C} \text {-statistic } \\
\text { model same } \\
\text { hospital }\end{array}$ & Significance & $\begin{array}{l}\text { r readmission } \\
\text { ratios same } \\
\text { versus any } \\
\text { hospital }\end{array}$ \\
\hline General surgery & 0.627 & 0.624 to 0.629 & 0.627 & 0.624 to 0.630 & - & 0.948 \\
\hline Cardiology & 0.610 & 0.607 to 0.613 & 0.623 & 0.620 to 0.627 & * & 0.787 \\
\hline Internal medicine & 0.600 & 0.597 to 0.603 & 0.606 & 0.603 to 0.609 & * & 0.916 \\
\hline Pulmonology & 0.625 & 0.621 to 0.628 & 0.630 & 0.626 to 0.633 & * & 0.930 \\
\hline Paediatrics & 0.587 & 0.582 to 0.591 & 0.581 & 0.577 to 0.586 & * & 0.901 \\
\hline $\begin{array}{l}\text { Gastroenterology and } \\
\text { hepatology }\end{array}$ & 0.599 & 0.594 to 0.603 & 0.598 & 0.594 to 0.603 & - & 0.956 \\
\hline Neurology & 0.613 & 0.608 to 0.618 & 0.616 & 0.611 to 0.621 & - & 0.820 \\
\hline Urology & 0.624 & 0.619 to 0.629 & 0.624 & 0.619 to 0.629 & - & 0.944 \\
\hline Orthopaedic surgery & 0.669 & 0.664 to 0.675 & 0.670 & 0.665 to 0.675 & - & 0.961 \\
\hline Obstetrics and gynaecology & 0.620 & 0.610 to 0.630 & 0.619 & 0.608 to 0.629 & - & 0.957 \\
\hline Cardiothoracic surgery & 0.633 & 0.623 to 0.644 & 0.665 & 0.653 to 0.677 & * & 0.802 \\
\hline Neurosurgery & 0.629 & 0.617 to 0.641 & 0.630 & 0.617 to 0.643 & - & 0.994 \\
\hline Ear, nose and throat clinic & 0.669 & 0.658 to 0.681 & 0.659 & 0.647 to 0.671 & - & 0.914 \\
\hline Clinical geriatrics & 0.595 & 0.583 to 0.607 & 0.593 & 0.581 to 0.606 & - & 0.986 \\
\hline Plastic surgery & 0.633 & 0.617 to 0.648 & 0.632 & 0.616 to 0.648 & - & 0.740 \\
\hline Anaesthesiology & 0.600 & 0.582 to 0.617 & 0.621 & 0.603 to 0.639 & * & 0.955 \\
\hline Rheumatology & 0.664 & 0.642 to 0.687 & 0.665 & 0.642 to 0.688 & - & 0.763 \\
\hline Ophthalmology & 0.610 & 0.582 to 0.638 & 0.596 & 0.566 to 0.626 & - & 0.648 \\
\hline Dermatology & 0.826 & 0.802 to 0.851 & 0.851 & 0.827 to 0.874 & * & 0.994 \\
\hline Oral and maxillofacial surgery & 0.679 & 0.648 to 0.709 & 0.685 & 0.653 to 0.718 & - & 0.369 \\
\hline Psychiatry & 0.670 & 0.613 to 0.728 & 0.700 & 0.642 to 0.757 & - & 0.920 \\
\hline Total & 0.641 & 0.640 to 0.642 & 0.646 & 0.645 to 0.647 & * & 0.905 \\
\hline
\end{tabular}

* Significant difference between C-statistic of model any hospital compared with model same hospital (95\% Cl)

of the delivered care. Based on the results of this study, it is not certain if readmissions in other hospitals reflect substandard quality of care. Therefore, it is advisable to explore the readmissions in other hospitals by record reviewing to reveal the reason for readmission, before it can be decided if these readmissions should be part of the readmission indicator.

Besides, there are two concerns when applying this in practice.

First, hospitals cannot calculate their own readmission rate which includes readmissions to other hospitals. Therefore, a national organisation is needed that monitors the data from all hospitals in a specific country and which can apply case mix adjustment to readmission ratios, required if a fair comparison between hospitals is to be achieved.

Second, it is illegal in the Netherlands to share information about the readmission to another hospital with the hospital to which the patient was first admitted, without specific consent from the patient. This means that learning from readmissions to other hospitals is complicated.
As a result of these concerns, we advise not to take into account readmissions to other hospitals in the Dutch readmission indicator.

\section{Future research}

In order to identify areas for improvement, it is necessary to assess unintended readmissions. However, based on administrative data only, it is difficult to assess whether a readmission was unintended. Previous research showed that about $30 \%$ of the readmissions are potentially preventable. ${ }^{14}{ }^{38}$ However, it is not known if this also applies to readmissions to other hospitals. Therefore, reviewing the records of readmissions to other hospitals is needed in order to analyse whether the readmission is a result of substandard care in the hospital where the original admission took place.

The group of patients who most often switch hospital, young men with relatively few comorbidities, may be interesting to explore further. For example, by using interviews to examine why they chose another hospital for their subsequent admission, in order to learn where quality can be improved. 


\section{CONCLUSION}

Overall, the impact on the readmission ratio of taking into account readmissions to other hospitals seems to be limited. We found $8.9 \%$ of the readmissions occur in another hospital, while $91.1 \%$ of the readmissions occur in the same hospital. However, for some hospitals, it does have consequences as $14 \%$ of the hospitals change their position of significance compared with the national average on the readmission ratio when taking into account readmissions to other hospitals. For these hospitals, it is interesting to explore what causes this difference and if it is related to the quality of care.

Contributors All authors contributed to the study design. $\mathrm{KH}$ analysed the data and produced the figures and tables. GPW, RBK, IB and SC provided input to the analysis and the interpretation of the results. The initial draft of the manuscript was prepared by KH. GPW, RBK, IB and SC critically revised the manuscript. All authors approved the final version of the manuscript.

Funding The authors have not declared a specific grant for this research from any funding agency in the public, commercial or not-for-profit sectors.

Competing interests None declared.

Patient consent for publication Not required.

Provenance and peer review Not commissioned; externally peer reviewed.

Data sharing statement The data used in this study are fully anonymised and publicly available for researchers via Remote Access to Statistics Netherlands (CBS) (costs may apply).

Open access This is an open access article distributed in accordance with the Creative Commons Attribution Non Commercial (CC BY-NC 4.0) license, which permits others to distribute, remix, adapt, build upon this work non-commercially, and license their derivative works on different terms, provided the original work is properly cited, appropriate credit is given, any changes made indicated, and the use is non-commercial. See: http://creativecommons.org/licenses/by-nc/4.0/.

\section{REFERENCES}

1. Fischer C, Lingsma HF, Marang-van de Mheen PJ, et al. Is the readmission rate a valid quality indicator? A review of the evidence. PLoS One 2014;9:e112282.

2. van Walraven $C$, Bennett $C$, Jennings $A$, et al. Proportion of hospital readmissions deemed avoidable: a systematic review. CMAJ 2011;183:E391-E402.

3. Westert GP, Lagoe RJ, Keskimäki I, et al. An international study of hospital readmissions and related utilization in Europe and the USA. Health Policy 2002;61:269-78.

4. Lagoe RJ, Nanno DS, Luziani ME. Quantitative tools for addressing hospital readmissions. BMC Res Notes 2012;5:620.

5. Bradley EH, Sipsma H, Horwitz LI, et al. Hospital strategy uptake and reductions in unplanned readmission rates for patients with heart failure: a prospective study. J Gen Intern Med 2015;30.

6. Hansen LO, Young RS, Hinami K, et al. Interventions to reduce 30-day rehospitalization: a systematic review. Ann Intern Med 2011;155:520-8.

7. Laudicella M, Li Donni P, Smith PC. Hospital readmission rates: signal of failure or success? J Health Econ 2013;32:909-21.

8. Kristensen SR, Bech M, Quentin W. A roadmap for comparing readmission policies with application to Denmark, England, Germany and the United States. Health Policy 2015;119:264-73.

9. Ashton CM, Kuykendall DH, Johnson ML, et al. The association between the quality of inpatient care and early readmission. Ann Intern Med 1995;122:415-21.

10. Chung ES, Lin Guo, Casey DE, et al. Relationship of a quality measure composite to clinical outcomes for patients with heart failure. Am J Med Qual 2008;23:168-75.

11. Encinosa WE, Hellinger FJ. The impact of medical errors on ninetyday costs and outcomes: an examination of surgical patients. Health Serv Res 2008;43:2067-85.
12. Rosen AK, Loveland S, Shin M, et al. Examining the impact of the AHRQ Patient Safety Indicators (PSIs) on the Veterans Health Administration: the case of readmissions. Med Care 2013;51:37-44.

13. Halfon $P$, Eggli $Y$, van Melle $G$, et al. Measuring potentially avoidable hospital readmissions. J Clin Epidemiol 2002;55:573-87.

14. Blunt I, Bardsley M, Grove A, et al. Classifying emergency 30-day readmissions in England using routine hospital data 2004-2010: what is the scope for reduction? Emerg Med J 2015;32:44-50.

15. Hechenbleikner EM, Makary MA, Samarov DV, et al. Hospital readmission by method of data collection. J Am Coll Surg 2013;216:1150-8.

16. Nasir K, Lin Z, Bueno $\mathrm{H}$, et al. Is same-hospital readmission rate a good surrogate for all-hospital readmission rate? Med Care 2010;48:477-81.

17. Halfon P, Eggli Y, Prêtre-Rohrbach I, et al. Validation of the potentially avoidable hospital readmission rate as a routine indicator of the quality of hospital care. Med Care 2006;44:972-81.

18. Metcalfe D, Olufajo OA, Zogg CK, et al. Unplanned 30-day readmissions in orthopaedic trauma. Injury 2016;47:1794-7.

19. Moore L, Stelfox HT, Turgeon AF, et al. Rates, patterns, and determinants of unplanned readmission after traumatic injury: a multicenter cohort study. Ann Surg 2014;259:374-80.

20. Luu NP, Hussain T, Chang HY, et al. Readmissions After Colon Cancer Surgery: Does It Matter Where Patients Are Readmitted? J Oncol Pract 2016;12:e502-e512.

21. Kim H, Hung WW, Paik MC, et al. Predictors and outcomes of unplanned readmission to a different hospital. Int J Qual Health Care 2015;27:513-9.

22. Davies SM, Saynina O, McDonald KM, et al. Limitations of using same-hospital readmission metrics. Int J Qual Health Care 2013;25:633-9.

23. Parreco J, Buicko J, Cortolillo N, et al. Risk factors and costs associated with nationwide nonelective readmission after trauma. J Trauma Acute Care Surg 2017;83:126-34.

24. Dutch Health Care Inspectorate. Basisset kwaliteitsindicatoren ziekenhuizen 2016. Utrecht, 2015:164-7.

25. DHD. Landelijke Basisregistratie Ziekenhuiszorg (LBZ). Available: https://www.dhd.nl/producten-diensten/lbz/paginas/ dataverzameling-lbz.aspx (accessed 18 Dec 2017).

26. Horwitz L, Partovian C, Lin Z, et al. Hospital-Wide All-Cause Unplanned Readmission Measure. Final Technical Report: Yale New Haven Health Services Corporation/Center for Outcomes Research \& Evaluation, 2012

27. Sacks GD, Dawes AJ, Russell MM, et al. Evaluation of hospital readmissions in surgical patients: do administrative data tell the real story? JAMA Surg 2014;149:759-64.

28. Yam $\mathrm{CH}$, Wong EL, Chan FW, et al. Measuring and preventing potentially avoidable hospital readmissions: a review of the literature. Hong Kong Med J 2010;16:383-9.

29. Peng M, Li B, Southern DA, et al. Constructing Episodes of Inpatient Care: How to Define Hospital Transfer in Hospital Administrative Health Data? Med Care 2017;55:74-8.

30. Nolte E, Roland M, Guthrie S, et al. Preventing emergency readmissions to hospital. A scoping review. Santa Monica: RAND corporation, 2011.

31. CBS. HSMR 2016: Methodological report. 2017.

32. Hekkert K, Kool RB, Rake E, et al. To what degree can variations in readmission rates be explained on the level of the hospital? a multilevel study using a large Dutch database. BMC Health Serv Res 2018;18:999.

33. Kansagara $\mathrm{D}$, Englander $\mathrm{H}$, Salanitro $\mathrm{A}$, et al. Risk prediction models for hospital readmission: a systematic review. JAMA 2011;306:1688-98.

34. Vest JR, Gamm LD, Oxford BA, et al. Determinants of preventable readmissions in the United States: a systematic review. Implement Sci 2010;5:88.

35. Gonzalez AA, Shih T, Dimick JB, et al. Using same-hospital readmission rates to estimate all-hospital readmission rates. J Am Coll Surg 2014;219:656-63.

36. Khan A, Nakamura MM, Zaslavsky AM, et al. Same-Hospital Readmission Rates as a Measure of Pediatric Quality of Care. JAMA Pediatr 2015;169:905-12.

37. Eurostat Database. OECD Health Statistics 2016. 2016. [Epub ahead of print Jun 2016].

38. Hekkert K, van der Brug F, Borghans I, et al. How to identify potentially preventable readmissions by classifying them using a national administrative database. Int J Qual Health Care 2017;29:826-32. 